\title{
Lithium treatment in cluster headache, review of literature
}

\author{
M.B. Abdel-Maksoud MBChB, MRCPsych* \\ A. Nasr MBChB, MSc, MRCPsych** \\ A. Abdul-Aziz MBChB, MSc ${ }^{\star \star \star}$ \\ * ST4 in Addiction Psychiatry, The Wells \\ Road Centre, The Wells Road, Nottingham \\ ** Consultant Psychiatrist, Queen Elizabeth \\ Psychiatric Hospital, Birmingham \\ *** Senior House Officer, Queen Elizabeth \\ Psychiatric Hospital, Birmingham \\ UNITED KINGDOM
}

\begin{abstract}
Background: The pain, which is involved in Cluster Headache (CH), is excruciating and is probably one of the most painful conditions known to humans. In the early 70 es it was found out that lithium could be used in treating this rare condition. Ekbom produced his first report of using lithium successfully to treat five cases of $\mathrm{CH}$ and this was followed later by other studies, which showed the effectiveness of lithium in this condition.

Objective: In this article we reviewed the evidence for using lithium in $\mathrm{CH}$. We discuss some issues including the duration, the dosage of lithium required and the short and longterm side effects, which are likely to occur. We also included the mechanism of action of lithium in treating this condition.

Methodology: We searched the Medline database from 1950 to date. We included all studies done in English, which were related to the use of lithium in cluster headache. We excluded all studies which were not in English and which included other types of headache.

Results and conclusions: We concluded that lithium is effective in both chronic and episodic forms of cluster Headache.
\end{abstract}

Received 9 January 2008

Revised 2 December 2008

Accepted 11 December 2008 


\section{Introduction}

$\mathrm{CH}$ is a rare condition, which is characterized by severe explosive pain, which lasts for less than three hours and occurs mainly in males. There are two forms of $\mathrm{CH}$ namely the chronic and the episodic forms. In the chronic form, the attacks occur for more than one year without remission or with remission lasting less than 1 month. In the episodic form, the attacks occur in periods lasting 7 days to 1 year separated by pain free periods lasting 1 month or longer. The pain is strictly unilateral in the orbital, supra-orbital, and or temporal region and associated with ipsilateral cranial autonomic symptoms and signs such as conjunctival injection, lacrimation, nasal congestion, rhinorrhea, miosis, and low grade ptosis. Most patients are restless or agitated during an attack $^{1}$. Cluster Headache has been shown to be associated with dysfunction in the nervous system, notably with involvement of the hypothalamus. Attacks occur with remarkable regularity and are related to REM sleep. They are followed by refractoriness for few hours and tend to have a seasonal pattern ${ }^{2}$.

Graham suggested that the effect of lithium on cluster headache may be, because this disorder shares several characteristics with manic depressive disease ${ }^{3}$.

\section{Studies}

Karl Ekbom did the first study when he treated 5 patients with $\mathrm{CH}$ (3 with chronic $\mathrm{CH}$ and 2 with episodic $\mathrm{CH}$ ). Serum lithium level was maintained between $0.7 \& 1.2 \mathrm{~m}$ $\mathrm{Eq} / \mathrm{l}$. Lithium was found to be effective in all 5 patients ${ }^{2}$.
In another study by Bussone et al., 20 patients with a diagnosis of chronic $\mathrm{CH}$ were treated with lithium carbonate. The doses of lithium varied from $900 \mathrm{mg}$ to $2.2 \mathrm{gm} /$ day. All patients improved rapidly on treatment and once treatment was stopped in some patients the headache returned within 36 hours ${ }^{4}$.

Later on, Kudrow treated a group of 32 patients suffering from chronic $\mathrm{CH}$ with lithium carbonate. The patients had previously tried different medications including methysergide, prednisone, and ergotamine without any result. Serum lithium levels were maintained lower than $1.2 \mathrm{mEq} / \mathrm{l} .27$ patients showed a dramatic improvement, whereas the therapy was found to be ineffective in 5 patients ${ }^{5}$.

Mathew undertook another clinical trial of lithium carbonate on 31 patients with $\mathrm{CH}$ (14 episodic, and 17 chronic). $80 \%$ of the patients responded to lithium and only $20 \%$ showed no improvement. Effectiveness of lithium was evident in less than a week after the initiation of treatment in those who responded. $55 \%$ of patients showed mild side effects. Treatment was stopped in one patient only because of intolerable side effects ${ }^{6}$.

In a study by Peatfield, 31 patients with $\mathrm{CH}$ were given lithium carbonate and the serum lithium levels were maintained at 0.6-0.69mmol/l. 14 patients showed a marked improvement in the first week, and 10 patients showed a lesser improvement ${ }^{7}$.

Ekbom gave a further contribution in 1981 when he conducted a study on 19 patients ( 8 with chronic $\mathrm{CH}$ and 11 with episodic $\mathrm{CH}$ ). He tried lithium sulphate and lithium levels were maintained between 0.7 and $1.2 \mathrm{mmol} / \mathrm{l}$. Immediate partial remission occurred in all chronic cases. In 4 cases with episodic $\mathrm{CH}$ lithium was continued for 
several months which resulted in complete suppression of cluster periods. The rest of the patients with episodic $\mathrm{CH}$ had slight or no benefit ${ }^{8}$.

In a trial by Faustino Savoldi et al., they included $90 \mathrm{CH}$ patients (68 with episodic\& 22 with chronic symptoms). In the $2^{\text {nd }}$ week of lithium treatment over $80 \%$ of the patients with chronic $\mathrm{CH}$ improved by more than $90 \%$. In the short term, some side effects occurred which were mild and tolerable. The doses of lithium varied from 600 to $1200 \mathrm{mg} /$ day and plasma lithium levels varied from 0.3 to $0.8 \mathrm{~m} \mathrm{Eq} / 1$. Of the 68 patients with episodic $\mathrm{CH}$, about $3 / 4$ improved by $>60 \%$. Mild side effects appeared in 18 cases (tremors, thirst, and insomnia). The plasma level varied from 0.3 to $0.7 \mathrm{~m} \mathrm{Eq/1}{ }^{9}$.

Manzoni et al. have investigated the short and long-term effects of administration of lithium carbonate ( $900 \mathrm{mg} /$ day) in 90 patients with $\mathrm{CH}$ (68 episodic and 22 chronic). $50 \%$ of the patients with chronic $\mathrm{CH}$ (11 patients) showed a definite improvement, whereas, $50 \%$ had initial or partial improvement only. In 9 cases, cessation of lithium resulted in reappearance of symptoms. In the episodic group, 26 patients responded highly, 26 patients responded partially, and 16 cases were refractory. Reversible goitre developed in 3 cases after 1-3 years of treatment ${ }^{10}$.

A double blind study by Bussone et al. compared the effect of Lithium and Verapamil in treating $\mathrm{CH}$ Showed that both Lithium and verapamil are effective in preventing Chronic $\mathrm{CH}$. They involved 30 patients diagnosed with Chronic $\mathrm{CH}$ according to the International Headache Society criteria $^{11}$. Regarding efficacy, both drugs significantly improved Headache Index (HI), and Analgesic Consumption (AC). Verapamil showed $>50 \%$ reduction in $\mathrm{HI}$ and
$58 \%$ in AC \& Lithium showed $>37 \%$ and $58 \%$ respectively in the $1^{\text {st }}$ week. Regarding Side effects, both drugs showed minor side effects (12\% for verapamil and 29\% for lithium $)^{12}$.

Steiner et al. conducted a double blind, placebo-controlled comparison of matched parallel groups of patients with episodic $\mathrm{CH}$ where treatment was slow release lithium carbonate, $800 \mathrm{mg} /$ day, or placebo. Substantial improvement occurred in $8 / 13(62 \%$ NS) on lithium and $6 / 14(43 \%)$ on placebo and the trial was stopped because superiority of lithium could not be demonstrated ${ }^{13}$.

There are other case reports which showed the effectiveness of lithium carbonate in treating both forms of $\mathrm{CH}$. Wyant \& Ashenhurst reported five cases of patients who had a diagnosis of $\mathrm{CH}$ (4 chronic and 1 episodic). They tried lithium carbonate and later on added amitriptyline for patients with chronic $\mathrm{CH}$ and lithium carbonate only for the patient with episodic $\mathrm{CH}$. Complete remission occurred in the patient with episodic $\mathrm{CH}$ and 1 patient with chronic $\mathrm{CH}$. A significant improvement occurred in 3 patients with chronic $\mathrm{CH}^{14}$.

In 1978, Lieb \& Zeff reported two cases with severe chronic $\mathrm{CH}$ to the extent that they had suicidal ideations. Both cases responded dramatically to lithium carbonate with serum levels of $0.76-1.15 \mathrm{mEq} / \mathrm{l}^{15}$.

Kilmek et al. used lithium carbonate to treat 15 patients with $\mathrm{CH}$ (8 chronic and 7 episodic). In all cases lithium serum level was maintained at 0.6-1.2 mmol/1. Disappearance of symptoms occurred in 5 patients ( 1 chronic and 4 episodic) and significant improvement occurred in 5 patients (4 chronic and 1 episodic). The treatment was ineffective in 5 patients ( 3 chronic and 2 episodic) ${ }^{16}$. 
In an open trial, Damasio \& Lyon tried lithium carbonate on 21 patients with $\mathrm{CH}$ (9 episodic, 12 chronic). $52.4 \%(n=11)$ of patients showed absolute improvement, $23.8 \%$ $(\mathrm{n}=5)$ showed partial improvement, and $23.8 \%(\mathrm{n}=5)$ did not improve or had temporary improvement only. Two patients had to discontinue treatment due to side effects ${ }^{17}$.

J M S Pearce reported 3 cases of episodic $\mathrm{CH}$ which responded dramatically to lithium carbonate at a dose of $250 \mathrm{mg}$ tds. No side effects were observed from lithium use ${ }^{18}$.

In 1980, Manzoni and Terzano tried lithium carbonate at gradually increased doses in 6 patients with chronic $\mathrm{CH}$. The effective dose of lithium varied from 300 to $900 \mathrm{mg} /$ day $^{19}$.

Zuddas et al. reported a case of chronic $\mathrm{CH}$ on haemodialysis treatment where lithium was used and led to a complete recovery ${ }^{20}$.

\section{Mechanism of action of lithium}

Some trials have been undertaken in an attempt to understand how lithium works in patients with Cluster Headache.

Kupfer et al. $^{21}$ and Mendels \& Chernik ${ }^{22}$ reported that the immediate action of lithium in treating $\mathrm{CH}$ is related to its effect on REM sleep.

In another study by Medina et al., it was found that lithium effect on $\mathrm{CH}$ is related to its effect on platelet serotonin and histamine levels ${ }^{23}$.

It was also suggested that lithium action in $\mathrm{CH}$ can be attributed to its effect on opiate receptor affinity ${ }^{24}$.

Giacovazzo et al. studied the relationship between genetic markers of patients with
$\mathrm{CH}$ and the therapeutic efficacy of lithium. In this study, 35 patients with episodic $\mathrm{CH}$ were involved. Lithium level was kept between 0.7 and $1.2 \mathrm{mEq} / \mathrm{l}$. Two subgroups were identified (responders $\mathrm{n}=21$ and non responders $n=14$ ). Responders displayed a higher frequency of the antigens HLA-B18 and HLA-A9 than did the non responders. The latter, on the other hand, showed a higher frequency of HLA-A1 than did the responders $^{25}$.

It was also found that lithium can correct the bilateral neuronal asymmetries which are related to the pathogenesis of $\mathrm{CH}^{26}$.

In a study by De Bellaroche et al., it was found that lithium restored the erythrocyte choline concentrations which were markedly reduced in patients with $\mathrm{CH}$. This finding was consistent with a subsequent study which showed a decreased turnover in the erythrocyte phosphatidylcholine in $\mathrm{CH}$ sufferers $^{27,28}$.

Winter et al. suggested that the mechanism of action of lithium in $\mathrm{CH}$ lies behind its antiviral actions ${ }^{29}$. This was based on the theory which suggests an association between $\mathrm{CH}$ and herpes simplex ${ }^{30}$.

A study by $\mathrm{G}$ Chazot et al. showed the chronobiological effect of lithium in cluster headache. The result showed a decrease in melatonin amplitude at day 0 in the cluster group together with a rise in the cortisol. However in day 7 there was a delay in melatonin secretion with a shift but clear increase of the acrophase was observed. A decrease in cortisol level was also observed ${ }^{31}$.

The cyclic nature and hormonal alterations in $\mathrm{CH}$ indicate the involvement of the hypothalamus in the pathogenesis of this disorder. One possible mechanism of action of lithium is its effect on the serotonin level in the hypothalamus ${ }^{32}$. 


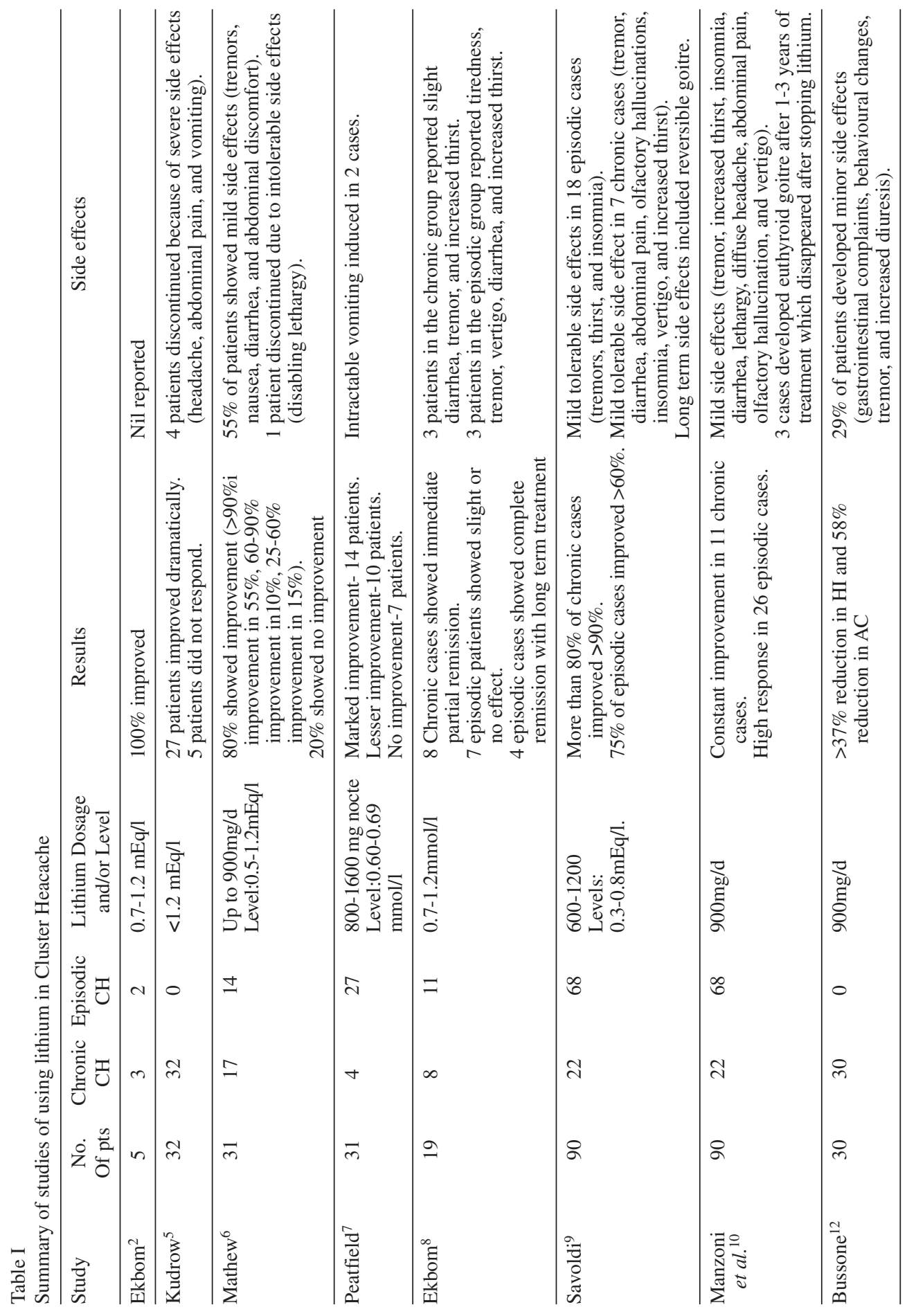




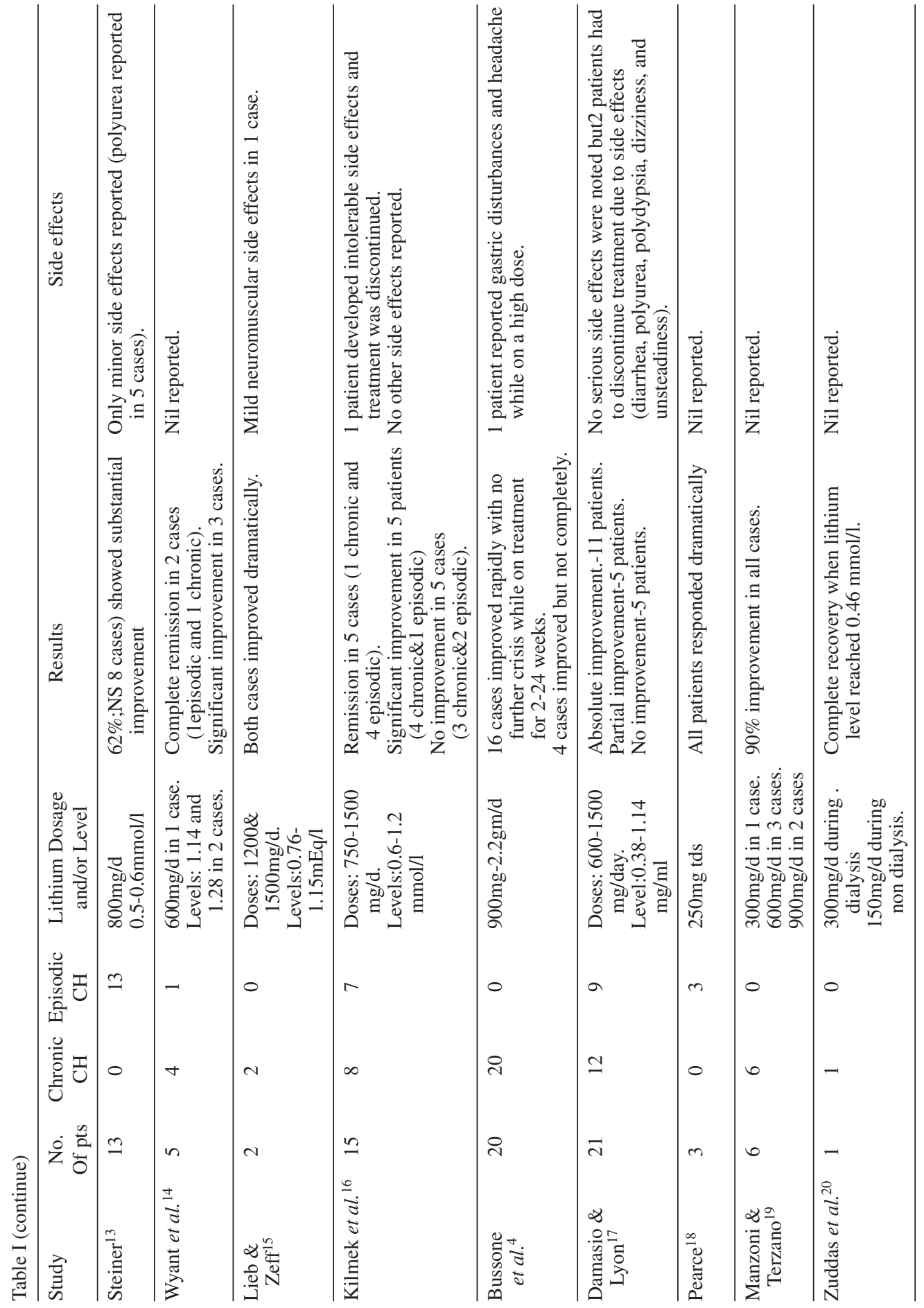




\section{Discussion}

We concluded from our review that lithium can be effective in both types of cluster headache but, perhaps, the evidence of its effectiveness in episodic forms is rather controversial. Some authors found that there is a decrease in the effectiveness of lithium after prolonged use in this condition. This may be due to tolerance or lack of compliance for one reason or another. There is a controversy regarding the required dose of lithium in patients with $\mathrm{CH}$ and some authors required higher doses to reach a plasma level between 0.7-1.2 $\mathrm{mmol} / \mathrm{l}$. Others, on the other hand, found that low doses of lithium with plasma levels between $0.4-1.0 \mathrm{mmol} / \mathrm{l}$ should be adequate for this condition.

In the short term the side effects of lithium are generally tolerable and they are mainly in the form of fine hand tremors, polyurea, and polydypsia. In the long term, hypothyroid goitre and renal impairment may develop. Hypothyroidism secondary to long-term lithium treatment can be treated and should not be an indication to stop lithium in stable clients. It is important that patients be well informed as to the needs for periodic lithium blood level determinations and the adverse as well as the beneficial effects of the drug.

It should be noted that with exception of the two studies done by Bussone et al. ${ }^{12}$, and Steiner et $a l .{ }^{13}$, results have been derived solely from open clinical trials.

Although there are different theories behind the mechanism of action of lithium in treating $\mathrm{CH}$, however, it remains unclear to how exactly it works and produces its rapid effect in this condition.

\section{References}

1. International Classification of Headache Disorders, $2^{\text {nd }}$ edition. Cluster Headache and other trigeminal autonomic cephalalgias. Cephalalgia 2004; 24 (Suppl. 1): 44-45.

2. Ekbom K. Lithium in the treatment of chronic cluster headache. Headache 1977; 17: 39-40.

3. Graham JR. Treatment of cluster headache (workshop), Sixteenth Annual Meeting, American Association For the study of Headache. June, 1974.

4. Bussone G, Boiardi A, Merati B, Crenna P, Picco A. Chronic Cluster Headache: response to lithium treatment. J Neurol 1979; 221: 181-185.

5. Kudrow L. Lithium prophylaxis for chronic cluster headache. Headache 1977; 17: 15-18.

6. Mathew NT. Clinical subtypes of cluster headache and response to lithium therapy. Headache 1978; 18: 26-30.

7. Peatfield RC. Lithium in migraine and cluster headache: a review. J R Soc Med 1981; 74: 432-436.

8. Ekbom K. Lithium for cluster headache: Review of the literature and preliminary results of long term treatment. Headache 1981; 21: 132-139.

9. Savoldi F, Bono G, Manzoni GC, Micieli G, Lanfranchi M, Nappi G. Lithium salts in cluster headache treatment. Cephalalgia 1983; 1: 80-84.

10. Manzoni GC, Bono G, Lanfranchi M, Micieli G, Terzano MG, Nappi G. Lithium carbonate in cluster headache: assessment of its short and long term therapeutic efficacy. Cephalalgia 1983; 3: 109-114.

11. Headache Classification Committee of the International Headache Society: Classification and Diagnostic Criteria for Headache Disorders, Cranial Neuralgias and facial pain. Cephalalgia 1988; 8(suppl. 7): 1-96.

12. Bussone G, Leone M, Peccarisi C, Micieli G, Granella F, Magri M, et al. Double blind comparison of Lithium \& Verapamil in Cluster Headache Prophylaxis. Headache 1990; 30: 411-417.

13. Steiner TJ, Hering R, Couturier EGM, Davies PTG, Whitmarsh TE. Double Blind Placebo-Controlled trial of lithium in episodic cluster headache. Cephalalgia 1997; 17: 673-675.

14. Wyant GM, Ashenhurst EM. Chronic pain syndromes and their treatment in Cluster Headache. Canad Anaesth Soc J 1979; 26: 1: 38-41.

15. Leib J, Zeff A. Lithium Treatment of Chronic Cluster Headache. Brit J Psychiat 1978; 133: 556-558. 
16. Klimek A, Szulc-Kuberska J, Kawiorski S. Lithium Therapy in Cluster Headache. Euro Neurol 1979; 18: 267268.

17. Damasio H, Lyon L. Lithium Carbonate in the Treatment of Cluster Headache. J Neurol 1980; 224: 1-8.

18. Pearce JMS. Chronic Migrainous Neuralgia. Brain 1980; 103: 149-159.

19. Manzoni GC, Terzano MG. Lithium carbonate in chronic cluster headache: assessment of therapeutic efficacy and possible mechanisms of action. Ital J Neurol Sci 1980; 1: 149-153.

20. Zuddas A, Mulas S, Del-Zompo M, Corsini GU. Cluster Headache: clinical efficacy of lithium salts in haemodialysis treated patient. Cephalalgia 1985; 5: 95-98.

21. Kupfer DJ, Wyatt RJ, Greenspan K, Scott J, Snyder F. Lithium Carbonate and sleep in affective illness. Arch Gen Psychiat 1970; 23: 35-40.

22. Mendels J, Chernik DA. The effect of lithium carbonate on the sleep of depressed patients. Int Pharmacopsychiatry 1973; 8: 184-192.

23. Medina JL, Fareed J, Diamond S. Lithium carbonate therapy for cluster headache. Arch Neurol 1980; 37: 559563.

24. Gillin JC, Hong JS, Yang HY, Costa E. (Met5) Enkephalin content in brain regions of rats treated with lithium. Proc Natl Acad Sci USA 1978; 75: 2991-2993.

25. Giacovazzo M, Martelletti P, Romiti, Gallo MF, Luvara E. Relationship between HLA System in Cluster Headache and Clinical Response to lithium Therapy. Headache 1985; 25: 268-270.

26. Fanclullacci M, Pietrini U, Boccuni M, Gatto G, Cangi F. Does lithium balance the neuronal bilateral asymmetries in cluster headache? Cephalalgia 1983; 3: 85-87.
27. De Belleroche J, Cook GE, Tresidder I, Joseph R, Das I, Clifford R. Erythrocyte choline concentrations and cluster headache. Br Med J 1984; 288: 268-270.

28. De Bellaroche J, Kilfeather S, Das I, Rose FC. Abnormal membrane composition and membrane dependant transduction mechanisms in cluster headache. Cephalalgia 1986; 6: 147-153.

29. Winter MD, Hartley CE, Randall SL, Mcleish P, Skinner GRB, Horrobin DF, et al.: The antiviral effects of lithium. Rev Contemp Pharmacother 1993; 4: 259-268.

30. Jose R, Rose FC. Cluster headache and herpes simplex: an association? Br Med J 1985; 290: 1625-1626.

31. Chazot G, Claustrat B, Brun J, Zaidan R. Effect on the Pattern of Melatonin and Cortisol in Cluster Headache of Single Administration of Lithium at 7.00 p.m. daily over one week: A Preliminary report. Pharmacopsychiatry 1987; 20: 222-223.

32. Friedmann E, Wang HY. Effect of chronic lithium treatment on 5-hydroxy tryptamine and release of 5- $(3 \mathrm{H})$ Hydroxytryptamine from rat brain cortical, hyppocampal and hypothalamic slices. J Neurochem 1988; 50: 195-201.

Address for correspondence:

Dr. M B Abdel-Maksoud

ST4 in Addiction Psychiatry, The Wells Road Centre,

The Wells Road,

Nottingham,

NG3 3AA.

U.K.

Tel.: 01159691300 ext.:11122

Fax: 01159529422

E-mail: mamaksouduk@yahoo.co.uk 